\title{
Percutaneous Nephrolithotomy for Large and/or Complex Renal Stone: A Pro spective-Multicentre Study
}

\author{
ALAA A. EL SHENNAWY, M.D.*; AHMAD SEDDIQ, M.D.*; SAMI A. ABBAS, M.D.*; \\ MOHAMED FAWZY, M.D.*; EHAB N. EISSA, M.D.** and AYMAN M. EDREES, M.D.*** \\ The Departments of Urology*, Anesthesia**, National Institute of Urology \& Nephrology and \\ The Department of Urology, Al-Azhar University, Girls Div. ***, Cairo, Egypt
}

\begin{abstract}
Background: Percutaneous Nephro-Lithotomy (PNL) is a well-established technique for removal of renal stones. Large and complex renal stones are difficult stones to deal with.

Aim of Study: This study is to evaluate our results of PNL for treatment of large and complex renal stones concerning Stone Free Rates (SFR) and complications.

Patients and Methods: From 2012 to 2017, four hundreds and four renal units with large and/or complex renal stones were subjected to PNL. Eighty nine percent were males and $11 \%$ were females. Average stone Surface Area (SA) was $872 \mathrm{~mm}^{2}$

Results: Stone Free Rate (SFR) was $79 \%$ for cases submitted to PNL alone and $88.4 \%$ for those managed with auxiliary procedures. Hospital stay ranged from 2 to 21 days (Av. 3.6 days). Overall complication rate was $8 \%$ and were managed conservatively.

Conclusion: PCNL is a safe and effective procedure for management of large and complex renal stones. There was a significant decrease in overall stone free rate and increased complication rates with increased stone surface area. Stones $>1500 \mathrm{~mm}^{2}$ are difficult stones for any modality. Multimodal approach should be thought of for large and complex renal stones.
\end{abstract}

Key Words: Kidney - Kidney calculi-Percutaneous nephrolithotomy - Intracorporeal lithotripsy - Large complex - Minimally invasive.

\section{Introduction}

SINCE its introduction into the endourologist's armamentarium almost 40 years ago [1], Percutaneous Nephrolithotomy (PNL) has become the standard of care for patients with large volume nephrolithiasis.

Correspondence to: Dr. Alaa A. El Shennawy, The Department of Urology, National Institute of Urology and Nephrology, Cairo, Egypt
Innovations in renal access, optics, radiology, and improvements in lithotripsy all contributed to that modern day PNL is the minimally invasive procedure of choice for removing large and complex renal stones [2].

\section{Patients and Methods}

Between March, 2012 and September 2017, three hundreds eighty two patients with 404 renal units (bilateral in 22 cases) were diagnosed as having large and/or complex renal stones. They were managed by Percutaneous Nephro-Lithotomy (PNL) in two institutes (National Institute of Urology and Nephrology and Al-Azhar University, Girls Div., Urology Dept).

Inclusion criteria involved patients with large $\left(\mathrm{SA}>300 \mathrm{~mm}^{2}\right.$ ) and/or complex (Table 1) renal stones. Stone burden was measured according to stone surface area (SSA) formula shown in Fig. (1) on plain UT [3], planimeter [4] or NCCT software [5].

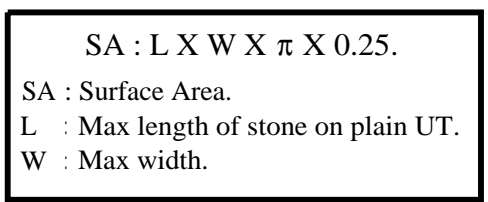

Fig. (1): Stone surface area formula [3]

Eighty-nine percent of patients were males and $11 \%$ were females. Mean age was 49.3 years (11$81 \mathrm{ys})$.

Table (1): Complex renal stones.

Multiple

Complete stag

Partial stag

Caliceal infundibular stenosis

Caliceal diverticulum

Others 
All patients were evaluated pre-operatively as regards urinalysis and urine culture, coagulation profile and renal function tests. Patients with pyuria were treated with proper antibiotics according to culture and sensitivity tests (antibiograms) and all patients were operated upon with sterile urine. In cases with resistant pyuria, the procedure was done under cover of proper antibiotics and the collecting system was drained preliminary by percutaneous nephrostomy. Yet, stone removal was accomplished in successive sessions. All patients with bleeding diathesis were excluded.

Imaging of the urinary tract was carried out by plain UT and abdomino-pelvic ultrasonography (US) in all cases. On diagnosis of renal stones, Non-Contrast Computed Tomography (NCCT) or Excretory Urography (EXU) were done for detailed anatomy of the pelvi-caliceal system.

\section{Technique:}

Most of the cases were operated upon under general anaesthesia. Epidural anaesthesia was used when indicted (14.8\% of PNL sessions). Epidural catheter was inserted targeting level between T6T8. Sensory assessment was done using pinprick and motor assessment by Bromage score.

Opacification of the collecting system was usually achieved by Retro-Grade Pyelography (RGP). Ultrasonography (US) was used to localize the upper tract in few cases. In all cases the procedure was completed under full fluoroscopic control.

Patients were positioned prone in most of the cases. Supine position (36 cases) was used in patients with high Body Mass Index (BMI).

Access to the pelvi-caliceal system was carried out through lower posterior calyx in most of the cases. Middle or upper calices accesses were also tried. Supracostal puncture was attained when necessary. Single puncture was performed in most of the cases and multiple punctures in complex renal stones. Dilation of the tract was done by Alken sequential telescopic metal dilators or balloon dilator. Ampltz sheath with safety guide wire insertion was followed in all cases.

Lithotripsy of the stone (s) was done by Pneumatic and/or ultrasound lithoclasts in most of the cases. Ho-Yag Laser was used with flexible nephroscopy or ureteroscopy. Nephrostomy tube was inserted after completion of the procedure (18-20 $\mathrm{CH}$ ) in most of the cases.
Post-operative control KUB films were attained for determination of Stone Free Rate (SFR). Ultrasonography and/or NCCT were done for lucent stones. Stone fragments $\geq 4 \mathrm{~mm}$ were considered as a failure. Antigrade nephrostogram was done when clinically indicated (post-operative pain, fever, persistent leak, suspected pelvi-caliceal injuries ...etc.).

\section{Statistics:}

Univariate analyses ( $\chi 2$ and $t$-test) and Pearson correlation model were used to determine factors affecting complications and stone-free rate. The data were analyzed using Statistical Package for Social Sciences, version 22 (SPSS Inc., Chicago, IL). A $p$-value of $<0.05$ was considered statistically significant.

\section{Results}

Four hundreds and four renal units in 382 patients with large and/or complex renal stones were managed by PNL in two different institutes between March 2012 and September 2017. The mean SSA was $872 \mathrm{~mm}^{2}$ (Table 2). Complex renal stones were diagnosed in $54.2 \%$ of cases (Tables 4,6 ).

Table (2): Stone surface area $\left(\mathrm{mm}^{2}\right)$.

\begin{tabular}{cccc}
\hline Min & Max & Mean & \pm SD \\
\hline 491 & 2551 & 872.4 & 401.9 \\
\hline
\end{tabular}

Stones were single in $83.5 \%$ (338) and multiple in $16.5 \%$ (66) (Table 3). Stone distribution and configuration is shown in Table (5). Radio-opaque stones were diagnosed in $67 \%$ and lucent in $33 \%$ of cases.

Table (3): Stones size and number.

\begin{tabular}{lll}
\hline & Single & Multiple \\
\hline No $(\%)$ & $338(83.5)$ & $66(16.5)$ \\
Mean SSA $( \pm$ SD) & $905(429.2)$ & $704(93.2)$ \\
\hline
\end{tabular}

Recurrent (open or endoscopic) cases were recorded in $28 \%$ while $72 \%$ were fresh cases.

Table (4): Complex renal stones.

\begin{tabular}{lll}
\hline Complex stones & $\mathrm{N}$ & $\%$ \\
\hline Multiple & 66 & 16.3 \\
Complete stag & 85 & 21 \\
Prtial stag & 65 & 16.1 \\
Infundibular stenosis & 2 & 0.5 \\
Caliceal diverticulum & 1 & 0.3 \\
\hline Total & 219 & 54.2 \\
\hline
\end{tabular}


In 286 cases $(70.8 \%)$ a single tract procedure was carried out and in 118 cases (29.2\%) multiple tracts were done. Access was gained through the posterior lower calyx in most of the cases $(73 \%)$. Puncture of the middle (18\%) or upper calyx (7.7\%) was performed according to stone site, number and configuration (6 cases had supracostal puncture). The procedure was completed in one session in $76 \%$ of cases and in two sessions in $24 \%$ of cases. Three sessions procedure was needed in only 2 cases.

Table (5): Stone distribution and configuration.

\begin{tabular}{lllllll}
\hline \multirow{2}{*}{ No } & \multicolumn{2}{c}{ Single } & \multicolumn{2}{c}{ Multipe } & \multicolumn{2}{c}{ Total } \\
\cline { 2 - 7 } Site & $\mathrm{N}$ & $\%$ & $\mathrm{~N}$ & $\%$ & $\mathrm{~N}$ & $\%$ \\
\hline Pelvic & 170 & 42 & 12 & 3 & 182 & 45 \\
Caliceal & 12 & 3 & 20 & 5 & 32 & 8 \\
Pelvic \& caliceal & $150^{*}$ & 37 & 32 & 8 & 182 & 45 \\
Kidney \& upper ureter & 6 & 1.5 & 2 & 0.5 & 8 & 2 \\
\hline Total & 338 & 83.5 & 66 & 16.5 & 404 & 100 \\
\hline
\end{tabular}

*: Complete and partial stag stones.

The mean operative duration was 95min $( \pm 23)$ ranging from 55 to $150 \mathrm{~min}$. Nephrostomy tube was removed post-procedural in a mean of 2.8 (110) days. Mean hospital stay was 3.6 (2-2 1) days.

The procedure was completed with PNL alone in $86.1 \%$ of cases and with auxiliary procedures in $13.9 \%$ (flexible ureteroscopy in $6.2 \%$ and SWL in $7.7 \%$ of cases).

Table (6): Stone in calices with infundibular stenosis and caliceal diverticulum.

\begin{tabular}{lcc}
\hline Stone site & $\begin{array}{c}\text { Infundibular } \\
\text { stenosis }\end{array}$ & $\begin{array}{c}\text { Caliceal } \\
\text { diverticulum }\end{array}$ \\
\hline Caliceal single & 2 & 1 \\
Multiple & 4 & 2 \\
Pelvic \& caliceal & 4 & 3 \\
\hline Total & 10 & 6 \\
\hline
\end{tabular}

Stone Free Rate (SFR) was 79\% for PNL alone and $88.4 \%$ with auxiliary procedure. Stone free rate demonstrated a significant relation with the stone surface area $(p=0.039)$ and complexity of the stone $(p=0.015)$. No significant relation was found between SFR and stone site or number (Table 7). Univariate analysis showed statistically significant relation between SSA and tract numbers, sessions, operative time, nephrostomy tube duration and hospital stay $(p<0.001)$. No significant relation was recorded between SA and the need to auxiliary procedures (Table 8).
Table (7): SFR relations

\begin{tabular}{lc}
\hline Stone free rate & $p$ \\
\hline SSA & 0.039 \\
Site & 0.143 \\
Complexity & 0.015 \\
Stone No & 0.770 \\
\hline
\end{tabular}

Table (8): SSA relations.

\begin{tabular}{lc}
\hline Stone surface area & $p$ \\
\hline${\text { Tract } \mathrm{N}^{\mathrm{o}}}_{\text {Session } \mathrm{N}^{\mathrm{o}}}$ & $<0.001$ \\
Operative time & $<0.001$ \\
Hospital stay & $<0.001$ \\
Nephrostomy tube duration & $<0.001$ \\
Auxiliary procedure & $<0.001$ \\
\hline
\end{tabular}

Complications recorded (Table 9) were bleeding that necessitated blood transfusion, persistent leak, infection, perforation, arterio-venous fistula with a total rate of $8.3 \%$. No need for conversion to open surgery was recorded.

Table (9): Complicatins and their managements.

\begin{tabular}{llll}
\hline Complication & No & $\%$ & Management \\
\hline Bleeding & 8 & 2 & Blood transfusion \\
Persistent leak & 10 & 2.5 & JJ stent \\
Infection & 8 & 2 & JJ stent + antibiotics \\
Perforation & 4 & 1 & JJ stent \\
A-V fistula & 2 & 0.5 & Angioplasty \\
Colon injury & 1 & 0.3 & JJ stent + conserve \\
\hline Total & 33 & 8.3 & \\
\hline
\end{tabular}

There was a significant relation between complication rate and tract number $(p=0.032)$ and multiplicity of sessions $(p=0.01)$. Complication rate showed no significant relation with SA, stone site, complexity, multiplicity, operative time, hospital stay or nephrostomy tube duration (Table 10).

Table (10): Complication relations.

\begin{tabular}{lc}
\hline Complications & $p$ \\
\hline SSA & 0.165 \\
Stone site & 0.646 \\
Complexity & 0.441 \\
Multiplicity & 0.494 \\
Tract No $^{o}$ & 0.032 \\
Session N & 0.010 \\
Operative time & 0.087 \\
Hospital stay & 0.090 \\
Nephrostomy tube duration & 0.091 \\
\hline
\end{tabular}

\section{Discussion}

Management of renal stones is a major issue for most urologists. Technological advances and changing treatment patterns have had an impact 
on current treatment recommendations, which have clearly shifted towards endourologic procedures [6].

Although early on SWL was used almost indiscriminately for the management of upper tract calculi, the limitations of the technique for large and complex stones became evident over time and PCNL became firmly established in the therapeutic armamentarium of nephrolithiasis [7]. PNL efficacy is little affected by stone size. Stones $>20 \mathrm{~mm}(>300$ $\mathrm{mm}^{2}$ ) should therefore be treated primarily by PNL because SWL often requires multiple treatments [8]. The European Association of Urology guidelines [9] and the American Urological Association (AUA) guidelines [10] recommend PCNL for the treatment of renal stones $>2 \mathrm{~cm}\left(>300 \mathrm{~mm}^{2}\right)$. In our study, average SSA was $>847 \mathrm{~mm}^{2}(30 \mathrm{~mm})$.

Increasing expertise and technical modifications have expanded the role of PNL to include complex renal calculi, staghorn calculi (complete or partial) and multiple large bulk calculi [1] . PCNL monotherapy for complex renal calculi has high success and clearance rates combined with minimal morbidity [11]. In our study, complex renal stones represented $52 \%$ of cases.

The American Urologic Association Guidelines for the Management of Staghorn Calculi stated, "Percutaneous nephrolithotomy should be the first treatment used for most patients with stones" [12] In UK, $30 \%$ of stones managed by PNL were staghorn calculi [13]. In our study, staghorn calculi represent $21 \%$ of cases.

Since 2000, PNL has made open surgery for complex renal stones obsolete in most countries [2]. Most urological centres worldwide report a need for open surgery in only $1-5.4 \%$ of the cases. However, in developing countries, the rate of open stone surgery refers to up to $14 \%$ [14]. The most common current indications for open stone surgery include those with a complex stone burden; failure of ESWL or endourological treatment; anatomical abnormalities, morbid obesity, concurrent open surgery, renal transplantation, severe limb contractures and patient preference [20]. Even nephrectomy may be performed when the involved kidney has negligible function [19]. In our series, no conversion to open surgery was needed.

For large and complex stones, multiple percutaneous accesses are often needed for stones removal from separate locations. However, the use of multiple accesses carries a higher risk of bleeding and complications compared with single access $[\mathbf{2 1 , 2 2}]$. Multiple access tracts are needed in as many as $20 \%$ to $58 \%$ of percutaneous procedures. These multiple PNL access tracts are known to increase the risk of renal parenchymal injury [23-26]

In our study, 1/3 of cases were subjected to multiple tracts and this was significantly related to stone surface area and increased rate of complications.

Operative time of an average of 65-112min was reported in PNL procedures for large and/or complex renal stones $[\mathbf{2 7 , 2 8 ]}$. It was directly related to stone size.

This study showed operative time of an average of 95min (55-150). It had a statistically significant relation with SSA.

One of the most important factors in selecting the optimal surgical modality for the patient with nephrolithiasis is stone size because size has been shown to strongly influence SFR, need for secondary procedures, and complication rate [7]. Stonefree rate for cumulative stone burdens $<20 \mathrm{~mm}$ for both URS and SWL are acceptable and have less morbidity than PNL. Of these treatment options, PNL stone free rates are the least affected by stone size, while stone-free rates of both SWL and URS decline with increasing stone burden [29]

For stones with SSA averages ranging 345$1128 \mathrm{~mm}^{2}$ managed with PNL monotherapy, SFR ranged $49-92 \%[27,30]$. In our study, SSA ranged $490-2250 \mathrm{~mm}^{2}$ and SFR was $79 \%$ for PNL monotherapy and $88 \%$ with auxiliary procedures.

Osman and his colleagues [31] reported a $67 \%$ of their patients were sufficiently treated by PNL, but $33 \%$ needed auxiliary measures. Hamamoto et al., [32] reported a $40 \%$ need for ancillary treatment. Auxiliary procedures were needed in only $14 \%$ of our patients.

Nephrostomy tube is placed at the end of Percutaneous Nephrolithotomy (PNL) to aid in hemostasis and drain the pelvicaliceal system [33]. Historically, a large bore catheter was placed at the end of the procedure and left indwelling for several days to provide drainage and tamponade the nephrostomy tract. The advantages of a large-bore catheter include reliable and efficient drainage, maintenance of the tract for a secondary procedure and prevention of bleeding from the tract. However, larger tubes are thought to be associated with increased patient discomfort and may in fact not limit post-operative blood loss as initially thought [7]. However, smaller size tubes $(<20 \mathrm{~F})$ required 
less analgesia, less urinary leakage and a shorter hospital stay $[\mathbf{3 4 , 3 5 ]}$.

In our study, an 18-20CH nephrostomy tube was fixed at the end of most of cases. Tube was left for an average of 2.8 days (1-10) with smooth post-operative course.

Recently, tubeless approach showed less cost, post-operative pain, hospital stay and earlier return to normal activities than standard PNL [36].

The goal of any surgical stone procedure is complete stone removal. Although the single procedure SFR for PNL is high $[\mathbf{3 7}, \mathbf{3 8}]$, the likelihood of residual fragments for large renal calculi is as high as 67\%, using strict CT criteria [39].

Any $4 \mathrm{~mm}$ residual fragments can be safely left behind after PCNL [40-42]. Postprocedural imaging to detect residual stone burden typically includes plain films, US, CT, and/or antegrade nephrostogram. CT is the optimal post-PCNL imaging modality to detect residual fragments [39].

In this series, cases with residual fragments $\geq 4 \mathrm{~mm}$ were considered as a failure. Post-operative control KUB films were done in most of cases. Ultrasonography and/or NCCT were done in selected patients (lucent stones).

Multiple studies reported hospital stay of 2-7 days post PNL for large renal stones $[28,30]$. This was ominously related to stone burden. On the other hand, Xue and his colleagues [43] stated that large renal stone size was statistically significantly associated with increased mean operative time but not with increased hospitalization.

In our series, an average of 3.6 days (2-21) was reported for hospital stay. It demonstrated a significant relation with SSA.

Complication rates reported in the literatures associated with PNL ranged $0-32 \% \quad[27,28,30,44]$ They including extravasation, need for transfusion, and fever. Higher rates were reported when multiple tracts were needed $[\mathbf{2 6 , 4 5 , 4 6 ]}$.

In our study, we reported a total complication rate of $8.3 \%$ and all were managed conservatively. Significant relation was recorded with multiple tracts and multiple sessions. No significant relation was found with SSA, complexity, stone site, operative time or nephrostomy tube duration.

Epidural Anaesthesia (EA) is a safe alternative to General Anaesthesia (GA) for PNL with better pain relief, less PONV and hospital stay. Hypoten- sion due to sympathetic blockade is always a possibility. Post-operative shivering is higher in EA patients [47]. Patients' and surgeons' satisfaction is higher in GA cases [48]. EA has lower rates of postoperative fever [49], lower fluoroscopy, time and less post-operative complication rates [50].

In our series, EA cases was used in $15 \%$ of PNL sessions. They showed less PONV and need to post-operative analgesia. They also represented less patients' and surgeons' contentment (patient' $s$ awareness and mobility).

\section{Conclusion:}

The propagation of minimally invasive PNL was developed in an effort to reduce the morbidity and mortality associated with open renal surgery but still represents the most morbid of the minimally invasive surgical modalities for renal stone removal.

However, in recent years, efforts to reduce the morbidity and increase the effectiveness and efficiency of the procedure are developing. In particular, micro and ultramini techniques are in their infancy and require further investigation. Also, efforts to increase SFR of Retrograde Intra-Renal Surgery (RIRS) and Flexible Ureteroscopy (FURS) are put forth.

Both GA and EA are effective and safe in PNL. EA has fewer complications and lower consumption of post-operative analgesia. However, GA provides more satisfaction for patients and surgeons.

\section{References}

1- FERNSTROM I. and JOHANSSON B.: Percutaneous pyelolithotomy. A new extraction technique. Scand J. Urol. Nephrol., 10 (3): 257-9, 1976.

2- KHURSHID R.G., SERO A., MATTHEW B., et al.: Percutaneous Nephrolithotomy: Update, Trends, and Future Directions. Eur. Urol., 70: 382-96, 2016.

3- TISELIUS H.G.: How efficient is extracorporeal shockwave lithotripsy with modern lithotripters for removal of ureteral stones? J. Endourol., 22: 249-55, 2008.

4- BANDI G., MEINERS R.J., PICKHARDT P.J., et al.: Stone measurement by volumetric three-dimensional computed tomography for predicting the outcome after extracorporeal shock wave lithotripsy. BJU. Int., 103: 524,2009

5- LAM H.S., LINGEMAN J.E., RUSSO R. and CHUA G.T.: Stone surface area determination techniques: A unifying concept of staghorn stone burden assessment. J. Urol., 148 (3 Pt 2): 1026-9, 1992.

6- CHRISTIAN T., ALES P., KEMAL S., et al.: EAU Guidelines on Interventional Treatment for Urolithiasis. Eur. Urol., 69: 475-482, 2016. 
7- JODI A.A. and MARGARET S.P.: Advances in Percutaneous Nephrolithotomy. Urol. Clin. N. Am., 40: 99-113, 2013.

8- PEARLE M.S., NADLER R., BERCOWSKY E., et al.: Prospective randomized trial comparing shock wave lithotripsy and ureteroscopy for management of distal ureteral calculi. J. Urol., 166: 1255-60, 2001.

9- SHENG L., TONG Z.L., XING-HUAN W., et al.: Randomized Controlled Trial Comparing Retroperitoneal Laparoscopic Pyelolithotomy Versus Percutaneous Nephrolithotomy for the Treatment of Large Renal Pelvic Calculi: A Pilot Study. J. Endourol, 28: 946-50, 2014.

10- DEAN A., AMY K. and NICOLE L.M.: Surgical Management of Stones: American Urological Association Endourological Society Guideline, PART II. J. Juro., 196: 1161-9, 2016

11- KHALAF I., SALIH E., EL-MALLAH E., FARGHAL S. and ABDEL-RAOUF A.: The outcome of open renal stone surgery calls for limitation of its use: A single institution experience. African J. Urol., 19: 58-65, 2013.

12- KUKREJA R.: PCNL Monotherapy for Complex Renal Calculi. Urology, 78 (suppl 3A): S104, 2011.

13- JAMES N.A., STUART O.I. and NEIL A.B.: Percutaneous Nephrolithotomy in the United Kingdom: Results of a Prospective Data Registry. Eur. Urol., 61: 1188-93, 2012.

14- RASSWEILER J.J., RENNER C. and EISENBERGER F.: The management of complex renal stones. BJU. Int., 86: $919-28,2000$

15- AL-KOHLANY K., SHOKEIR A., MOSBAH A., et al.: Treatment of complete staghorn stones: A prospective randomized comparison of open surgery compared with percutaneous nephrolithotomy. J. of Urol., 173: 469-73, 2005.

16- ASSIMOS D.G., BOYCE W.H., HARRISON L.H., et al.: The role of open surgery since extracorporeal shock wave lithotripsy. J. Urol., 142: 263-7, 1989.

17- SEGURA J.W.: Current surgical approaches to nephrolithiasis. Endoc. Met. Clin. N. Am., 19: 912-25, 1990.

18- PAIK M.L., WAINSTEIN M.A., SPIRNAK J.P., et al.: Current indications for open stone surgery in the treatment of renal and ureteral calculi. J. Urol., 159: 374-9, 1998.

19- ROCCO F., CASU M., CARMIGNANI L., et al.: Longterm results of intrarenal surgery for branched calculi: Is surgery still valid? BJU. Int., 81: 796-800, 1998.

20- EL-HUSSEINY T. and BUCHHOLZ N.: The role of open stone surgery. Arab. J. Urol., 10: 284-8, 2012.

21- NETTO N.R. Jr., IKONOMIDIS J., IKARI O., et al.: Comparative study of percutaneous access for staghorn calculi. Urology, 65 (4): 659-63, 2005.

22- KUKREJA R., DESAI M., PATEL S., et al.: Factors affecting blood loss during percutaneous nephrolithotomy: Prospective study. J. Endourol, 18 (8): 715-22, 2004.

23- DESAI M. and GANPULE A.P.: Management of the staghorn calculus: Multiple-tract versus single-tract percutaneous nephrolithotomy. Curr. Opin. Urol., 18: 2203, 2008.

24- DESAI M., JAIN P., GANPULE A., et al.: Developments in technique and technology: The effect on the results of percutaneous nephrolithotomy for staghorn calculi. BJU. Int., 104: 542-8, 2009.

25- EL-NAHAS A.R., SHOKEIR A.A., EL-ASSMY A.M., et al.: Postpercutaneous nephrolithotomy extensive hemorrhage: A study of risk factors. J. Urol., 177: 576-9, 2007.

26- MOUSAVI-BAHAR S.H., MEHRABI S. and MOSLEMI M.K.: Percutaneous nephrolithotomy complications in 671 consecutive patients: A single-center experience. Urol. J., 8: 271-6, 2011.

27- VALDIVIA J.G., SCARPA R.M., DUVDEVANI M., et al.: Supine versus prone position during percutaneous nephrolithotomy: A report from the Clinical Research Office Of The Endourological Society Percutaneous Nephrolithotomy Global Study. J. Endourol., 25: 161925, 2011.

28- WANG Y., WANG Y., YAO Y., et al.: Prone versus modified supine position in percutaneous nephrolithotomy: A prospective randomized study. Int. J. Med. Sci., 10: 1518-23, 2013.

29- SRISUBAT A., POTISAT S., LOJANAPIWAT B., et al.: Extracorporeal shock wave lithotripsy (ESWL) versus percutaneous nephrolithotomy (PCNL) or retrograde intrarenal surgery (RIRS) for kidney stones. Cochrane Database Syst. Rev., 11: CD007044, 2014.

30- ASTROZA G., LIPKIN M., NEISIUS A., et al.: Effect of supine vs prone position on outcomes of percutaneous nephrolithotomy in staghorn calculi: Results from the Clinical Research Office of the Endourology Society Study. Urology, 82: 1240-4, 2013.

31- OSMAN M., WENDT-NORDAHL G., HEGER K., et al.: Percutaneous nephrolithotomy with ultrasonography guided renal access: Experience from over 300 cases. BJU. Int., 96: 875-8, 2005.

32- HAMAMOTO S., YASUI T. and OKADA A.: Endoscopic Combined Intrarenal Surgery for Large Calculi: Simultaneous Use of Flexible Ureteroscopy and Mini-Percutaneous Nephrolithotomy Overcomes the Disadvantageous of Percutaneous Nephrolithotomy Monotherapy. J. Endourol., 28: 28-33, 2014.

33- BELLMAN G.C., DAVIDOFF R., CANDELA J., et al.: Tubeless percutaneous renal surgery. J. Urol., 157: 157882, 1997.

34- MAHESHWARI P.N., ANDANKAR M.G. and BANSAL M.: Nephrostomy tube after percutaneous nephrolithotomy: Large-bore or pigtail catheter? J. Endourol., 14 (9): 735-8, 2000.

35- PIETROW P.K., AUGE B.K., LALLAS C.D., et al.: Pain after percutaneous nephrolithotomy: Impact of nephrostomy tube size. J. Endourol., 17 (6): 411-4, 2003.

36- ZILBERMAN D.E., LIPKIN M.E., De La ROSETTE J.J., et al.: Tubeless percutaneous nephrolithotomy-the new standard of care? J. Urol., 184 (4): 1261-6, 2010.

37- DEEM S., DEFADE B., MODAK A., et al.: Percutaneous nephrolithotomy versus extracorporeal shock wave lithotripsy for moderate sized kidney stones. Urology, 78 (4): 739-43, 2011

38- ALBALA D.M., ASSIMOS D.G., CLAYMAN R.V., et al.: Lower pole I: A prospective randomized trial of extracorporeal shock wave lithotripsy and percutaneous 
nephrostolithotomy for lower pole nephrolithiasis initial results. J. Urol., 166 (6): 2072-80, 2001.

39- PEARLE M.S., WATAMULL L.M. and MULLICAN M.A.: Sensitivity of noncontrast helical computerized tomography and 112 Antonelli \& Pearle plain film radiography compared to flexible nephroscopy for detecting residual fragments after percutaneous nephrostolithotomy. J. Urol., 162 (1): 23-6, 1999.

40-PORTIS A.J., LALIBERTE M.A., HOLTZ C., et al.: Confident intraoperative decision making during percutaneous nephrolithotomy: Does this patient need a second look? Urology, 71 (2): 218-22, 2008.

41- RAMAN J.D., BAGRODIA A., GUPTA A., et al.: Natural history of residual fragments following percutaneous nephrostolithotomy. J. Urol., 181 (3): 1163-8, 2009.

42- RAMAN J.D., BAGRODIA A., BENSALAH K., et al.: Residual fragments after percutaneous nephrolithotomy: Cost comparison of immediate second look flexible nephroscopy versus expectant management. J. Urol., 183 (1): 188-93, 2010.

43- XUE W., PACIK D., BOELLAARD W., et al.: Management of Single Large Nonstaghorn Renal Stones in the CROES PCNL Global Study. J. Urol., 187: 1293-7, 2013.

44- AL-DESSOUKEY A.A., MOUSSA A.S., ABDELBARY A.M., et al.: Percutaneous nephrolithotomy in the oblique supine lithotomy position and prone position: A comparative study. J. Endourol., 28: 1058-63, 2014.

45- MICHEL M.S., TROJAN L. and RASSWEILER J.J.: Complications in percutaneous nephrolithotomy. Eur. Urol., 51: 899-906, 2007.

46-TEFEKLI A., ALI KARADAG M., TEPELER K., et al.: Classification of percutaneous nephrolithotomy complications using the modified Clavien grading system: Looking for a standard. Eur. Urol., 53: 184-90, 2008.

47- VIRKAR N.D., PATKAR G.A., ROHIT R. and TENDOLKAR B.A.: A comparative study of combined spinal epidural anaesthesia and general anaesthesia in patients undergoing percutaneous nephrolithotomy. Int. J. Res. Med. Sci.,4 (9): 3760-7, 2016.

48- MOAWAD H.S., EL HEFNAWY A.S. and SPINAL V.S.: General anaesthesia for percutaneous nephrolithotomy: A prospective randomized trial. Egy. J. Anesthesia, 31 : 71-5, 2015.

49- KIM S.S., LEE J.W., YU J.H., et al.: Percutaneous Nephrolithotomy: Comparison of the Efficacies and Feasibilities of Regional and General Anesthesia. Korean J. Urol., 54 (12): 846-50, 2013.

50- CICEK T., GONULALAN U. and DOGAN R.: Spinal anesthesia is an efficient and safe anesthetic method for percutaneous nephrolithotomy. Urology, 83 (1): 50-5, 2014.
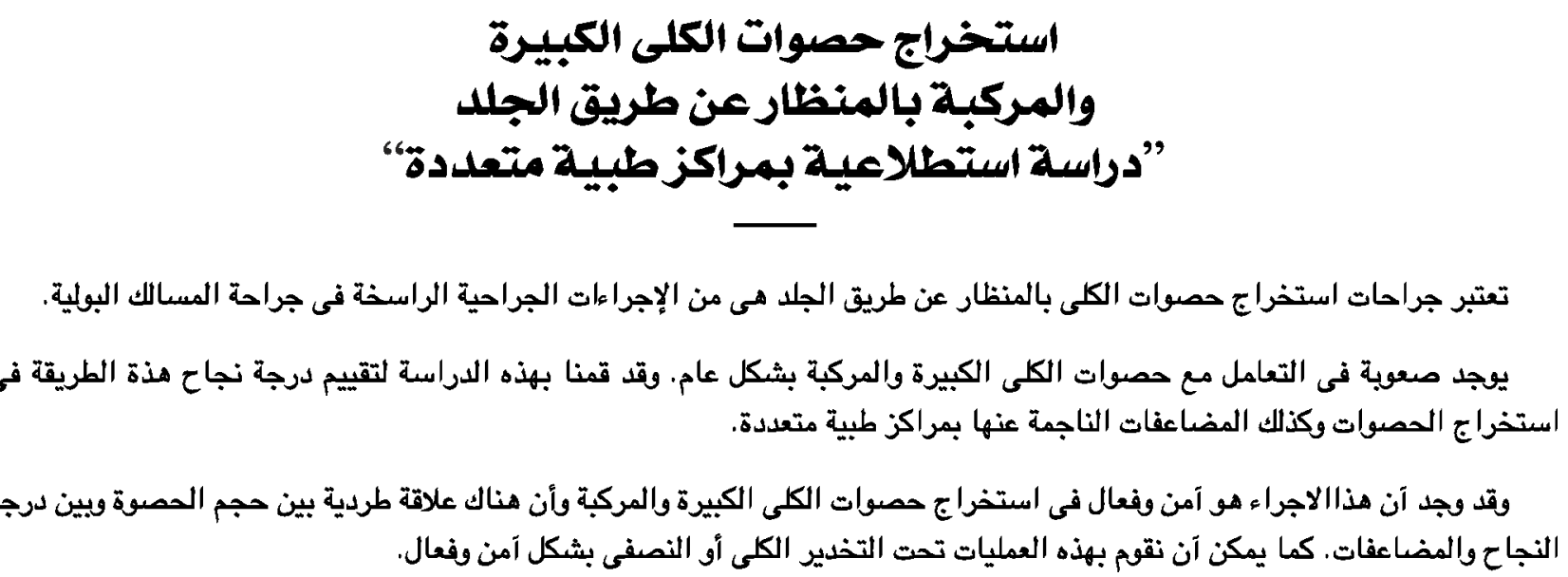